\title{
Interpreter-mediated CBT - a practical implementation guide for working with spoken language interpreters
}

\author{
Beverley Costa \\ Birkbeck University of London, 26 Russell Square, London WC1H 5DT, UK; www.pasaloproject.org \\ Email: beverley@pasaloproject.org
}

(Received 20 August 2021; revised 13 December 2021; accepted 13 December 2021)

\begin{abstract}
In the UK, over three-quarters of a million people cannot speak English well enough to access cognitive behavioural therapy (CBT) in English. If they are to receive an equitable service, they need to be able to access (spoken language) interpreter-mediated therapy. This means that CBT therapists may need support, through training and supervision, to feel confident and positive about incorporating an interpreter into the therapeutic relationship. The requirement for CBT therapists to be able to work effectively with an interpreter is currently acknowledged in the new BABCP minimum training standards and core curriculum, which are recommended for adoption (BABCP, 2021). Understandably, therapists can feel anxious about working with a third person in the room, but when these anxieties are honestly addressed and explored, creative solutions can be found. Therapy is usually conducted in a dyad. A triadic relationship requires attention to the systems at play inside and outside of the therapy room. With careful preparation and planning, interpreter-mediated therapy can be an effective and positive experience for the patient. After an introductory section, the paper is divided into six implementation sections: preparing for interpreter-mediated therapy; meta communication; boundaries; managing three-way relationships; working with interpreters remotely; and support needs of interpreters. Using a case example approach, interpreter-mediated therapeutic situations, which illustrate challenges and solutions, and examples of good practice, are explored. The paper offers practical guidance and illustrations which can form the basis of a training programme which teaches CBT therapists how to form a collaborative working relationship with an interpreter, how a therapist can stay active and maintain their clinical authority in a session in which they do not understand what is being said, and how CBT therapists can ensure that the therapy session remains safe and effective for all three of the participants in the interpreter-mediated encounter.
\end{abstract}

\section{Key learning aims}

(1) To help CBT therapists feel more confident and positive about working with spoken language interpreters.

(2) To prepare CBT therapists to create a more accessible service for those patients who do not speak sufficient English to engage in therapy without support.

(3) To provide CBT therapists with key principles for managing the pulls and pushes in a triadic relationship when you do not understand the language(s) spoken in the room.

Keywords: clinical authority; collaborative; interpreter; interpreter-mediated therapy; spoken languages 


\section{Introduction}

This article has been written as a practical implementation. This type of guide aims to draw on evidence from research and from clinical wisdom. By their nature, not every suggestion can be evidence-based at this stage [especially when there has been little research into interpretermediated cognitive behavioural therapy $(\mathrm{CBT})$ ], but I endeavour to be transparent on what is clearly based on research and what is based on the significant experience of the author. The author of this paper is from a psychotherapy and spoken language interpreting practice background. I have supervised, trained and interpreted extensively for a range of clinicians, including CBT therapists in IAPT services, and for the third sector for over 20 years. I have delivered training in interpreter-mediated therapy to over 2000 CBT and other therapists. The focus of this paper is on spoken language interpreting. Although some of this article may be applicable to working with sign language interpreters, the reader may wish to refer to the NHS Guidelines for Working with British Sign Language/English Interpreters in Mental Health Settings (https://www.rdash.nhs.uk/wp-content/uploads/2014/04/DP8403-Guidelinesfor-working-with-BSL-01.19.pdf) or the Association of Sign Language Interpreters (2020) for further information.

Beginning with an overview of the background to interpreter-mediated psychological therapy, the paper is then divided into six implementation sections: preparing for interpreter-mediated therapy; meta communication; boundaries; managing three-way relationships; working with interpreters remotely via video link or on the telephone; and support needs of interpreters.

This implementation paper is substantial in length. It is intended as a consultation guide. The section on preparation for interpreter-mediated therapy is the lengthiest. This is because time spent on careful preparation and building a collaborative relationship with an interpreter is the key to ensuring that interpreter-mediated therapy is effective. Some readers may prefer to consult each of the sections separately and others may find it more useful to read the paper in its entirety. The case examples are included to illustrate ways in which to make interpretermediated therapy as effective as possible for the patient.

\section{Background}

Over three-quarters of a million people in the UK report that they cannot speak English well, according to the 2011 Census in the UK. In some cases, they may be offered therapy in their first language. Working therapeutically across languages is a substantial topic which is worthy of attention. However, it is beyond the scope of this paper to deal with it appropriately. This paper focuses on what happens if any of those three-quarters of a million people need to access help with their mental health and they cannot be linguistically matched with a cognitive behavioural therapist or there is no lingua franca (the language both the patient and the therapist can converse in) (Bailey, 2019). A therapist will probably need to incorporate a spoken language interpreter ${ }^{1}$ into the working relationship if they are going to be able to work collaboratively with the patient. Patients (and therapists) also need to be able to have access to appropriately trained interpreters ${ }^{2}$ if they are truly going to experience equity of access to mental health services ${ }^{3}$. However, many therapists, understandably, feel anxious about incorporating a third person into what is traditionally a dyadic relationship (Boyles and Talbot, 2017; Doherty et al., 2010; Tutani et al., 2018), particularly when that third person

\footnotetext{
${ }^{1} \mathrm{~A}$ spoken language interpreter translates the spoken word. A translator translates the written word.

${ }^{2}$ Professional, trained interpreters work to the highest professional and ethical standards. Unfortunately, some interpreting agencies employ untrained interpreters. It is a good idea to check on an agency's quality control policies and procedures. These should be publicly available.

${ }^{3}$ It should be noted, however, that although most patients are grateful to have access to an interpreter, not all patients will welcome having to speak through an interpreter. It is important to check with the patient about their preference.
} 
seems to hold the power of enabling the communication between all three participants in the conversation. After all, an interpreter could add or detract from any part of the conversation and the patient and therapist would be none the wiser. For some therapists, this is the end of the story, despite a patient's appreciation of the effectiveness of interpreter-mediated therapy (Costa and Briggs, 2014). Some therapists just decide that they are not going to work with an interpreter. The consequence is that patients who need a spoken language interpreter can languish on a waiting list if only a few therapists are prepared to work with an interpreter. This is acknowledged and reflected in the new BABCP minimum training standards and core curriculum, which are recommended for adoption. These standards include the requirement for CBT therapists to be able to work with interpreters psychotherapeutically, establishing ways of working together and considering clinical implications (BABCP, 2021).

There are of course challenges, but there are also assets to working with interpreters in CBT. The assets become clear when a clinician has thought about and planned for the session so that a collaborative relationship - or a mini-équipe (Salaets and Balogh, 2015) - can be formed between the interpreter and the therapist for the best outcome possible for patients.

Sometimes, interpreter-mediated therapy can even provide an enhanced therapeutic experience for patients. A patient may feel a greater sense of containment if their treatment is delivered by a collaborative pair of professionals who are working together in harmony, on their behalf. For the therapist, the benefit of working with an interpreter is that they have more time for reflection, formulation, and observation of the patient's body language while an interpreter is rendering the translations. Also, importantly, the experience of working with an interpreter, and attending with sensitivity to the inherent power dynamics, can sharpen up a therapist's practice with all their patients. This does not happen by chance. It requires careful thought, preparation, and/or supervision and training. This paper will provide a practical framework, illustrated by case examples, relevant for a CBT context. These case examples show what can go well and how to problem-solve and/or avoid things going wrong. The aim is for practitioners to feel more confident and work effectively with interpreters (and hopefully, to enjoy the process), so that patients receive an equitable and effective service, with positive therapeutic outcomes.

\section{The challenge}

As already noted, one of the biggest challenges for therapists is that traditionally clinical work is conducted between two people, and the idea of incorporating a third person into the relationship can be unsettling (Tribe and Thompson, 2009). This challenge is compounded by the fact that the clinician, who holds the clinical responsibility for the session, cannot understand what the patient is saying. It is therefore to be expected that this will create anxiety for a therapist. Clinicians report having sensations of 'exclusion and uncertainty and even competitive feelings' (Miller et al., 2005; p. 32). These feelings frequently result in therapists slipping into a passive stance. Many of the solutions to working effectively with interpreters involve therapists in re-evaluating their positions on the active-passive continuum of facilitation when they are working with an interpreter. CBT therapists who are used to taking a collaborative stance may find it takes a while to get used to being at the more active end of the continuum, at least until everyone has become familiar with the three-way process. Working at the active end of the continuum involves an increased attention to transparency, clarity and to the power dynamics in the room. These are all essential clinical skills, but because these clinical skills are put under additional pressure when working in a triad, specialist brief training and further support from appropriately trained supervisors is recommended. One unintended bonus of working with interpreters is that, as therapists increase their confidence in their clinical authority, the quality of their practice is enhanced with all patients regardless of their linguistic needs. 
In the following sections of the paper six over-arching practice issues, including one from a support/supervision perspective, will be explored through case examples. Potential solutions will be offered, concluding with tips for working effectively with interpreters in a mental health setting. These case examples illustrate material which is included in brief training programmes on effective interpreter-mediated therapy. The six issues are:

(1) Preparing for interpreter-mediated therapy;

(2) Meta communication ('talking about the talking');

(3) Boundaries;

(4) Managing three-way relationships;

(5) Working with interpreters remotely via video link or on the telephone;

(6) Support needs of interpreters.

\section{Preparing for interpreter-mediated therapy}

Effective interpreter-mediated therapy begins before the first session. This phase includes activities such as (i) booking an interpreter, (ii) organising and holding a pre-meeting with the interpreter and (iii) responding to family and friends' offers to interpret.

\section{Booking an interpreter}

Booking an interpreter is not a purely administrative task. Clinical responsibility includes ensuring safety for the patient, even if an interpreter is needed.

\section{Case example}

Gloria has recently joined a service as a CBT therapist. Gloria tries to book an interpreter for a session later in the week, but she is told that that the administration team is responsible for booking interpreters to make the booking process streamlined and effective for all. Gloria wonders: 'Where do the interpreters come from? Have they been vetted/assessed/inducted into our code of practice?'.

Later at the session, when the Turkish-speaking interpreter Mustafa arrives, it soon becomes clear to Gloria, in the patient's notes and in the pre-meeting, that her patient speaks Kurdish. Mustafa tries to reassure Gloria that the patient will be able to understand Turkish. During the session, Mustafa makes several asides to Gloria in which he expresses a negative opinion about the patient. The session does not go well, and Gloria makes a commitment to think about this carefully with her supervisor and to reflect on what she could have done differently. In the supervision session she identifies the need to stay active even before the interpreter-mediated session begins. She will try to take a systemic approach and consider all the elements of the system which are impacted before, during and after the session.

It is useful to liaise closely with the administration team if an interpreter is needed so that you can check that the correct language-matching has occurred and so that you can understand the criteria the administration staff are using to assess patients' linguistic abilities and linguistic needs. Interpreting agencies are unregulated, so you may want to find out about the interpreting agency your service uses. You can ask about the interpreting agency's codes of practice and its quality control measures. Many patients (although not all) prefer to have the same interpreter for their treatment, so that they do not have to repeat their story to multiple listeners. If that is a patient's preference or need, can the interpreting agency accommodate that requirement? One solution to relying on unregulated agencies is to create an in-house team of interpreters. The following description of interpreters' experiences of working directly with therapists within an 
Improving Access to Psychological Therapies (IAPT) service provides an example of service-wide good practice.

\section{Case example}

Usually, IAPT services work with interpreters from different agencies. The following example of a pilot scheme illustrates how interpreters can be incorporated into an IAPT service and the difference they can make for the therapeutic process. The pilot scheme lasted for 3 years. The small pool of interpreters representing different languages and trained in interpreting for mental health, became a part of a local IAPT service. The interpreters were employed directly by the NHS, but they were managed by the IAPT administration team. All the IAPT CBT therapists, counsellors and psychological wellbeing practitioners (PWPs) were given a list of interpreters with their spoken language, email address and telephone number. Usually, the whole booking process was done by the IAPT administration team. The therapists could also contact interpreters directly to find out their availability and/or discuss alternative dates and times. The direct contact between therapists and interpreters was very useful. It helped practitioners to have the same interpreter for the whole therapeutic process. It meant that both sides could develop a relationship and exchange CBT materials, questionnaire and booklets. From my point of view, as an interpreter, it was much easier to navigate the materials and interpret if we already knew what to expect. Sight or telephone translation of difficult questionnaires which are used in Step Three is very difficult, almost impossible without previous preparation. In briefings, therapists could discuss and explain to interpreters their methods of practice and their expectations. Interpreters could share their views and observations. All these procedures contributed to interpreters feeling like a key part of the therapeutic process and showed them that their work was being appreciated. This positive working relationship contributed to many successful, completed courses of therapy.

\section{Organising and holding a pre-meeting with the interpreter}

Professional interpreters and psychological therapists have their own professional codes of ethical practice. This paper focuses on how CBT practitioners can manage the specific ethical issues of power and safety when they are working with an interpreter. Power and safety are two major concerns for therapists working with interpreters. Patients may feel powerless and vulnerable. They are in a position where they need help, and they can neither understand the language of their helper nor make themselves understood in their own language. Therapists can feel powerless to communicate directly and they are dependent on the interpreter for that communication to take place. Interpreters feel powerless as they cannot make any independent intervention to alleviate the patient's issues. They are reliant on the therapist to do that. Powerlessness in interpreter-mediated helping situations can invoke a desire in professionals to compete with each other for control (Miller et al., 2005). A therapist will be concerned about whether they can guarantee that the therapy room is a safe space if they do not understand what is being said. They may also be concerned about establishing rapport with the patient and of staying in control of the session. Interpreters may be concerned that they will not understand any jargon used, that they may be emotionally overloaded, that their own safety could be compromised, or that they do not trust the clinician if, for example, they are unfamiliar with the working methods of therapy. Six CBT therapists and seven PWPs working in an NHS IAPT service were interviewed about their experiences of working with interpreters within an IAPT service (Tutani et al., 2018). One theme that emerged from the interviews was that practitioners found that working collaboratively with interpreters was a challenge because of a lack of shared understanding of each other's working methods.

Patients may wonder if the interpreter might be able to translate their feelings accurately. They may fear that their own voice will be lost. With fears on the three sides of the triangle, it is not 
surprising that this can feel daunting for practitioners, adding an extra level of complexity to the therapeutic work. Ideally a practitioner and an interpreter can feel that they are working on the same side, engaging in a team effort rather than a competition between rivals. Finding a way to work collaboratively together in the service of patients is a priority for therapists and interpreters. This requires the therapist and the interpreter to prepare together and to work as a collaborative team (also known as a mini-équipe; Salaets and Balogh, 2015). Therapists can enhance the chances of this happening if they make sure that they meet alone with the interpreter, before inviting the patient to join them, to prepare before the therapy session and then to de-brief after the session. The pre-meeting is an opportunity for the therapist to welcome the interpreter into the team and let the interpreter know that their professional skills are valued and respected. In the interests of transparency, it is useful to let the patient know that briefing meetings will take place and to inform the patient about the type of content that will be discussed.

\section{Example of the content of a pre-meeting}

Charlie, a CBT therapist, has arranged to have a pre-meeting with an interpreter called Lamia. He has never worked with her before, so he sets himself an agenda for the type of things they are going to discuss. He wants to leave enough time for anything Lamia wants to ask or tell him. He plans to share his working methods with Lamia if she is new to CBT. He explains how some behaviours of a clinician, e.g. not rushing to comfort a patient who is crying, or allowing silences in the room, may seem strange. But Charlie explains they are clinical strategies, not signs of incompetence. Charlie has also, in advance, sent a sample of the forms that are going to be used to the interpreter and they have already addressed any linguistic problems. They agree that all the form-filling will be done together (with all three of them) in the room and with the interpreter translating all the questions and responses orally.

As Charlie is aiming to use guided exposure therapy, he asks Lamia not to step in to try to alleviate the emotional disturbance for the patient, even though it may be difficult to resist. Charlie asks if Lamia can interpret consecutively ${ }^{4}$ and in first person so that he can feel more of a connection with the patient. They think about the logistics of role playing and chair work that Charlie plans to use. These are new concepts for the interpreter and may need some logistical planning together, e.g. how does the interpreter translate for a patient who is speaking from multiple roles?

Together, Charlie and Lamia discuss the frame for the work. Charlie explains that the therapeutic frame refers to the micro and the macro levels of structures which enable anxieties to be contained and worked with productively in mental health settings. Charlie proposes that he will probably set the ground rule that 'everything everyone says in the room will be translated out loud'. They agree that it will be Charlie, rather than Lamia, who sets the ground rules. They want to give a clear message to the patient about who is leading the sessions. It can be tempting to leave the setting of communication guidelines to the interpreter. But it can be confusing for a patient. Creating a safe psychological space (the therapeutic frame) is the responsibility of the clinician. If a clinician adopts a passive position in relation to this responsibility, giving the more active role of establishing the psychological safety to the interpreter, it is quite possible that a patient may start to have doubts about the clinician's competence to contain the session safely. It is therefore also agreed that Charlie will lead on the introductions, but he will invite Lamia to introduce herself so that she can reassure the patient that whatever she hears in the session she will treat as strictly confidential.

\footnotetext{
${ }^{4}$ Consecutive interpreting is interpretation of speech after the original speaker has paused or finished speaking, while simultaneous interpreting occurs in real-time, with the interpreter speaking at the same time as the patient speaking, without any pauses. For therapeutic communication, consecutive interpreting tends to be preferred so the patient's own voice can be heard first, by the practitioner, even if the practitioner does not understand the meaning of the words the patient is speaking.
} 
After this discussion there is time for Lamia to ask Charlie one thing. She asks him if he can remember to speak in small chunks and allow time for her to translate.

During Charlie's and Lamia's pre-meeting, Charlie had also mentioned that sometimes, if the patient understands and prefers to speak some of the time in English, the therapist, interpreter and patient will negotiate together how much needs to be translated in order for everyone to understand everything.

The following case example, written from an interpreter's perspective, illustrates how this can happen.

\section{Case example}

Shazia is an experienced Urdu interpreter. She's interpreting for a CBT therapist, called Laura, with whom she has worked on other occasions. Neither have worked with the patient before. During the triage session the assessor had felt that the patient didn't fully understand what was being said. The patient had dismissed the offer of an interpreter, but Shazia had still been booked. When the patient arrived at the CBT session, he said 'I have been in this country for over 25 years, and I speak English at work all the time. I don't need an interpreter'. However, Laura was able to reach an agreement with the patient that Shazia would only translate in the case that one of them didn't fully understand the other. Shazia was aware of the patient's need to be self-sufficient, and the session went ahead without any further issues.

Working together as a team, Laura and Shazia were able to manage a delicate situation. However, the following example, again, from an interpreter's perspective, illustrates what can happen when the opportunity for a pre-meeting has not been provided.

\section{Case example}

Simran, an interpreter, is booked in for a telephone interpreter-mediated CBT session with a Punjabi-speaking patient. It is a half an hour slot during which the therapist goes through the compulsory PHQ-9, GAD-7, Phobia Scales and Work and Social Adjustment Scale. It takes 10 minutes to explain the purpose of the call to the patient, who just wants to tell her story/ explain her situation. After each question Simran has to remind the patient to rate her problems/feelings with a number as the therapist keeps insisting upon it. This takes up the full 20 minutes with the final questions being rushed through.

If only they had allowed a double slot both the patient and the therapist would have got to the point they hoped to reach. They were all disappointed with the outcome as a second session had to be booked to complete what should have been done in one.

A therapist may also want to consider allowing time for the interpreter to share issues of cultural sensitivity.

The following example, told from an interpreter's perspective, illustrates how important cultural sensitivity can be for effective therapy to occur.

\section{Case example}

Danielle is carrying out an assessment session with Marta, a Portuguese patient. For this session Danielle has booked a Portuguese interpreter, Isabel. The session is proceeding well, and the communication and flow of conversation are working to everyone's advantage until Danielle asks Marta 'Now that I have all the relevant information, and I have explained the various ways in which we can support you, I was wondering what type of therapy you feel would be best for you?'. At this point, Marta looks at Isabel with a very baffled look on her face. 'What does she mean? I thought that as she is the professional, she would be the one telling me what the best form of treatment would be to help me. I don't know what to say'. Marta bursts into tears. Danielle is confused. What could she have said that has upset Marta so much? 
Patients may come from cultures that adopt different approaches to healthcare. They may not be familiar with an approach to treatment which involves tentative questioning or an invitation to collaborate in their own treatment. Had Danielle been aware of this, she may have thought of a different way to put this question. In the briefing session, Isabel could have mentioned that some patients from Marta's cultural background find a tentative approach from a clinician unsettling initially.

\section{Family and friends' (and clients' preferred interpreters) offers to interpret}

In a review of users' experiences of access to health and social care services via interpreters the researchers found that many service users preferred to have family members interpret for them. This may be because 'they trust them ... they have an ongoing relationship with them and an emotional commitment and loyalty towards each other' (Alexander, 2004; p. 60).

However, when family members acted as interpreters, their role was to give both practical and emotional support (Hadziabdic et al., 2014), and this led to both positive and negative emotions and outcomes. It is therefore recommended to work only with professional interpreters in therapeutic consultations (BABCP, 2019; Bernardes et al., 2010; Boyles and Talbot, 2017; British Psychological Society, 2017; Costa and Briggs, 2014; Doherty, 2010; Miller et al., 2005; Salaets and Balogh, 2015; Tribe and Lane, 2009.)

So how is the therapist's choice, to work only with a professional interpreter, reconciled with the patient's wish to be interpreted for by a family member? Rejecting the offer of a family member to interpret requires delicate and sensitive communication. It is good to show appreciation and respect for the support offered, but it is advisable to stick to the professional boundary of not commencing therapy while a family member is present.

\section{Case example}

Maria came for her first counselling session. Paramjit, her therapist, went to collect her from the waiting room, where she was sitting with her sister, Ana. In the waiting room, Ana explained to Paramjit that she would be interpreting for Maria. She said that she always did this and that this is what Maria wanted. Paramjit took them both into the therapy room where an interpreter was waiting. Via the interpreter (so that Maria would be included), she thanked Ana, the sister, for her support and explained that organisational policy meant that she would not be able to accept her kind offer. She asked Maria if she would be prepared to have one trial therapy session with the interpreter. They could then review together, afterwards, to see if Maria felt able to continue working in this way. Paramjit also asked Ana if later on, when the therapy had progressed, she could ask for her support, if relevant issues emerged in the sessions. This could include for example, asking Ana to accompany Maria to different, new activities. Maria and Ana agreed to give it a try.

It is easy for therapists to feel pulled into accepting a family member's generous offer to interpret. But as therapists, we need to think carefully about this kind of pull. It can feel counter-intuitive and persecutory not to accept a relative's offer of support (especially if this seems to be a patient's preference). Therapists can feel anxious about appearing culturally insensitive, ignoring families' preferences, values and systems. It is important to remember why you make a decision. Do you actively want to involve a family member in the treatment? Is this part of your therapeutic plan? Or did you just slide into accepting the offer of help? Even though the incorporation of family members is appropriate in some CBT treatments, it is acknowledged that: 'Without a clear framework, the involvement of family members in therapy can feel unstructured, unpredictable, and challenging' (Lobban and Barrowclough, 2016; p. 198) 
Paramjit demonstrates that she is making a conscious decision, not just reacting to a difficult situation. She uses the organisational policy to move the discussion away from personal preferences. Family members are, of course, involved in some formal CBT treatments, but in a reflectively organised way, not as a reactive response (Lobban and Barrowclough, 2016; Renshaw et al., 2005; Thirlwall et al., 2017).

Although Paramjit took the decision to respectfully invite Ana into the room, no therapeutic conversation took place, and no personal material was discussed. By treating Ana's offer with respect - by giving some of the power back to Ana (asking, rather than telling her, if she could contact her in the future), by valuing Ana's relationship with Maria, and by not rejecting her completely - Paramjit is able to build enough trust for the session to go ahead appropriately.

Another relational dilemma may be posed by professional interpreters who have worked with patients before, in other settings. Some interpreters have established long-term relationships with their patients (even though it may be advised against in interpreters' codes of practice). This can be problematic. It may make it difficult for a therapist to form a rapport with the patient. However, rather than declining to work with an interpreter outright (indeed, there may not be an alternative interpreter available), the therapist could explain why having an interpreter with whom the patient has a prior relationship could impede the therapy. The therapist could mention that for therapeutic work, it is important to create a therapeutic space where it is possible for the patient to remove herself from external influences in order to view and review the influences of the external world in multiple ways. The therapeutic space might be likened to the controlled space of a laboratory where people can experiment and try out new behaviours and responses. For this reason, it is usually helpful if all the people involved in the therapy do not have relationships outside of the therapy room. However, if the patient is still hesitant about bringing in an unknown interpreter, the therapist might suggest that they try a couple of sessions with the patient's preferred professional interpreter and then evaluate together how the therapy is progressing. They can then decide whether it is viable to continue as they are, or whether a different interpreter is needed and can be tolerated by the patient. Through the regular review structure, the therapist retains control of the session while remaining flexible. A therapist needs to be confident in their decision-making processes about this complex ethical issue. If the patient's safety may be compromised by having an over-involved interpreter in the therapy sessions, then a final option may be that the treatment does not go ahead. The therapeutic frame and ethical guidelines can be flexible but there need to be limits if the therapy is to stay within the domain of safe practice.

\section{Meta communication}

Everyone needs to know the rules of communication at the very beginning of the session. This involves (i) setting the communication ground rule and (ii) talking about how the communication will work, or 'talking about the talking'.

\section{Ground rule}

As we have already noted, three-way communication through an interpreter differs systemically from dyadic communication. We saw in a previous case example that it might be helpful to set a ground rule like this before anyone says anything else: 'Everything that everyone says in the room will be interpreted'. It can also be useful for the therapist to make a circular, inclusive hand gesture (if culturally appropriate) when they are setting the ground rule. This serves at least three purposes. Firstly, it emphasises that the rule applies to everyone. Secondly it is a direct form of the therapist's communication with the patient, and it helps with relationship building and 
the maintenance of an active therapist stance. Thirdly, if the therapist needs to remind everyone of the rule, they can simply repeat the gesture, which does not require translation.

Transparency is essential in all forms of CBT without an interpreter, of course. But interpretermediated communication requires an unswerving commitment to keep everyone in the loop. Of course, as a therapist or counsellor, if we want the interpreter to trust us to hold the authority, we have to do what we have said we will do, or unhelpful relational dynamics may be created as the following case example illustrates.

\section{Case example}

Saira is an interpreter. She has had a pre-meeting with the CBT therapist, Ann. Ann has explained that she will set down all the ground rules about the communication. Saira waits patiently at the beginning of the session for Ann to explain that everything that everyone says will be interpreted, but Ann seems to have forgotten to mention this. Saira thinks this is too important to neglect and so she intervenes and explains the ground rule in both the languages of the therapist and the patient. Ann is cross with herself for forgetting to set the ground rule, and she is cross with Saira for interrupting.

This case example and the next case are illustrations of how quickly clinical authority can slip away, and of how anxieties can be elicited and acted upon when mistakes are made, even when everyone's intentions are benign.

\section{'Talking about the talking'}

As a therapist, you may want to discuss aspects of the therapeutic communication before they become problematic. What will happen, for example if the patient wants to speak for a long time without interruption and the therapist cannot understand? Who takes the responsibility for managing this, and how? One option is for the therapist to suggest that the patient say whatever they need to say without interruption. Once they have finished, the patient is then requested to repeat what they have said in short chunks so that the interpreter can translate. The therapist can explain that this is for the patient to be able to express themselves freely first. The therapist can be included into the communication afterwards.

A therapist may be grateful to an interpreter who paraphrases, for the patient, terminology and jargon the therapist has used. A therapist may prefer to leave issues like this to the interpreter to sort out. But that leaves the therapist at the passive end of the continuum, with the interpreter taking on the responsibility for the communication.

\section{Case example}

Jenny is a CBT therapist working with a patient called Bushra, mediated through an interpreter called Sameera. Jenny wants to introduce the concept of obsessive compulsive disorder (OCD) to Bushra and asks her how much she knows about OCD. Sameera is pretty sure that Bushra won't understand the concept of OCD so she decides to 'translate' the concept into something Bushra can relate to. She says to Bushra, 'Do you keep washing your hands all the time?', and Bushra replies that she does not. Sameera 'translates' to Jenny that Bushra says she doesn't have a problem with this issue. Jenny leaves the line of questioning about OCD and doesn't discover that it takes Bushra 30 minutes to leave her house because she has to keep checking that the door is locked.

Succumbing to the temptation to solve troubling interpersonal communication between the participants in the system may result in ironic (or unintended) consequences (Dallos and Vetere, 2012). What seems like a facilitative intervention by the interpreter is, in fact, obstructive of the treatment.

This series of (lack of) decisions and actions illustrates how easily clinicians can become passive when they don't understand an interaction. It is not infrequent for a clinician to be so grateful to 
the interpreter for taking control that they forget the importance of their own therapeutic alliance and communication with the patient. Consequently, they lose their therapeutic footing. How can this be avoided? The prevention is better than cure approach can help a clinician to stay active. (This approach can also help interpreters manage their own professional and self-care needs; Bontempo and Malcolm, 2012.) In the pre-meeting the clinician can establish with the interpreter that they need everything translated. If the interpreter lets the clinician know that the patient doesn't understand something it is then the clinician's job to find the words that will reach the patient. If the clinician leaves paraphrasing to the interpreter, the clinician loses the clinical control of the message and, consequently, of the session. By engaging with the meta communication, talking about the talking - agreeing together with the interpreter the communicative strategy - this potentially harmful situation could have been avoided.

\section{Boundaries}

It is very difficult for interpreters to manage unboundaried conversations, where they may hear about safeguarding issues, or they may need to refuse requests from vulnerable patients for their telephone numbers. Receptionists will often seat interpreters and patients together in the waiting room. Therapists may leave interpreters and patients on their own together. What are the potential unwanted consequences of these actions?

\section{Case example}

Tom has just conducted a risk assessment with a new patient called Wanda. He needs to leave the room for a moment to collect a form. When he returns to the room, he can see that the interpreter, Pawel, looks uncomfortable. In the debrief, after the session, Pawel tells Tom that Wanda disclosed that she has been having suicidal thoughts. She asked Pawel not to tell Tom when he came back into the room. Pawel says he feels terrible because Wanda clearly felt she could trust him. He doesn't think Wanda will trust him any longer as she thought Pawel would keep her secret. But Pawel feels he has to tell Tom because of the potential risk. Tom wishes he had thought about the implications of leaving the interpreter and the patient alone together. He decides that the next time he needs to leave the room he will take the interpreter with him. Although the ground rule about risk and confidentiality had been set, it may be tempting for a patient to believe the rule need only apply if the clinician is present.

Systemic preparation, by therapists, includes thinking about how interpreters arrive and leave appointments without being left on their own to manage unfacilitated conversations with patients. Although a pre-meeting and a post-meeting debrief may be planned, patients and interpreters can still encounter each other in unplanned situations outside of the therapy room. One solution is for a clinician to have a conversation with the receptionist to ask them to seat interpreters, on arrival, in the staff room, away from patients. Also, as part of the 'talking about the talking' clinicians may want to discuss with patients the rationale for not continuing the conversation with the interpreter if they are left on their own together. This explanation for the patient (and for the interpreter) can make transparent why it is preferable if the interpreter does not interact with the patient beyond the clinician-facilitated therapy session.

\section{Managing three-way relationships}

The interpreter-mediated therapy triad is not exempt from the pulls and pushes inherent in triangular relationships. This has been explored extensively elsewhere (Boyles and Talbot, 2017; Hadziabdic et al., 2014; Costa and Briggs, 2014; Costa, 2011; Crezee et al., 2011; Messent, 2003; Tribe and Thompson, 2009). Our own histories of being in triangular 
relationships can trigger unhelpful behaviour. It is therefore important for CBT therapists to become aware of their own thoughts and feelings and interpersonal pulls (Safran and Segal, 1990).

\section{Case example}

Prudence has agreed to try cognitive restructuring to address her tendency to over-generalise some of her beliefs about the safety/lack of safety of travelling by bus. Prudence is from Cameroon and her therapy is mediated by a male French-speaking interpreter called Dominic. The CBT therapist is called Will. Prudence trusts Dominic, and Prudence and Dominic seem to have a good rapport together. Will feels that he needs to gain Prudence's trust so that she will engage fully in the cognitive restructuring work. Will has carefully laid out the seating in the room in an equilateral triangle. But despite Will's efforts Prudence does not look at him. Prudence is happy to make eye contact with Dominic but not with Will. Will understands that this is probably because Dominic speaks her language, but Will still finds that he feels annoyed with Dominic. Will blames Dominic for the lack of his own rapport with Prudence. Will starts to see Dominic as an opponent. Dominic notices that Will is angry and starts to experience Will as persecutory. Before long Will and Dominic both feel like victims, and Prudence doesn't know whether to try to rescue the situation or just go home.

Self-reflexivity on the part of the therapist and the interpreter can help to bring these complexities into the light. What are one's default behaviours and (sometimes unhelpful) coping strategies when one feels excluded? Is a different response needed in the interpretermediated triad? With awareness, these relational dynamics [also exemplified by Karpman's (1968) Drama Triangle] can be reflected on in supervision, not reacted to in the session (Costa, 2017). It is probably useful to discuss eye contact with the interpreter in the premeeting and to think together about how to manage the potential dynamic illustrated in the previous case example.

\section{Working with interpreters remotely via video link or on the telephone}

The British Psychological Society recommends using video conferencing for remote interpretermediated therapy rather than telephone interpreting where possible. Guidance about administrative issues for this type of work can be found here: https:/www.bps.org.uk/sites/ www.bps.org.uk/files/Policy/Policy\%20-\%20Files/Working\%20with\%20interpreters\%20online \%20or\%20via\%20the\%20telephone.pdf.

This account by an interpreter also illustrates some of the administrative issues.

\section{Case example}

Ivana is a Romanian interpreter. She received an email from the booking coordinator with a request for a video call assignment for four consecutive weeks and accepted it. On the booking confirmation she received a Microsoft Teams link. She thought that everything was fine, and she was not expecting any problems.

On the day of the first appointment, she used the link to join the meeting and was waiting for a practitioner to invite her into the room. But there was nobody there. Nobody contacted her by phone either. After 20 minutes of waiting, she contacted her agency who tried to reach the service but still it was unsuccessful. The same situation happened on the second and third week.

What went wrong? When booking an interpreter for a video or telephone call it is important to give the contact details of the interpreter, such as an email address and telephone number to the administration team/clinician. If possible, the interpreter should also be given a contact telephone number to be able to reach the service if something goes wrong. Using technology is a helpful 
alternative to face-to-face appointments. However, it is not always reliable. Thinking ahead and having a back-up plan, in this case having a telephone number or the interpreter's email address, is always good, to avoid the situation described in the case example.

The Royal College of Speech and Language Therapists has also produced guidelines for working with interpreters remotely which include useful guidance about the communication process: https://3959e25e-b3e4-4cf0-92ed-b4c50fc1442d.filesusr.com/ugd/7f9695_e2618d3af15c4 3d5ab5057ad54e5cd97.pdf

The following case example illustrates what can happen if communicative issues, when working with interpreters remotely, are not addressed.

\section{Case example}

A therapist, Ben, has an interpreter-mediated telephone session booked with a Mandarin-speaking patient, Pearl. Although a video call might have been better, for logistical reasons this hasn't been possible. But Ben has been working via the telephone with Pearl for two months and he feels the sessions have gone well. Their regular interpreter is on leave and so a different interpreter, called Huang, has been booked. When Huang joins the call, he seems keen to get started. Ben is pleased that there are no delays. Ben quickly reiterates the ground rule that everything will be translated, and they begin the session. As the call progresses, Pearl starts to explain why she was unable to complete the action plan/homework she and Ben had agreed she would do. She describes a serious incident that she witnessed near her house. Pearl is beginning to get distressed. At the same time, Ben can hear several noises in the background - running water and pans banging. It soon becomes clear that Huang is cooking a meal while interpreting. Ben is very cross and starts to get distracted from Pearl's narrative.

It is easy to forget that even on the telephone or on a video call a pre-meeting and a debrief with the interpreter is essential. This needs to be planned into the booking request. In this way the interpreter would have met (via the telephone) with Ben prior to the patient joining the call so that expectations about behaviour could have been clarified, together with the usual items on a pre-meeting agenda. Even if the session is short, or the therapist has worked with the patient before, it is important on a remote call to slow down introductions and ground rules so that everyone understands them. It is even more vital for the therapist to stay active and to find ways to engage directly with the patient. One way of doing that is to use people's names (more frequently than you would if you were all in a room together) to make a connection. Finally, immediately after the session, it is helpful to write down the issues and to make a plan for how to resolve them next time, together with the interpreter. If the sessions move between remote sessions and in-person sessions it is useful to re-contract for the new context at each transition.

\section{Support needs of interpreters}

Interpreters work in unpredictable and emotionally charged contexts with very little, if any, support. They appreciate being briefed about what they are going into and being debriefed at the end, so they can have a moment to take stock. The debrief can enable an interpreter to share cultural information, give feedback to the therapist about whether they need to adapt their communication for the interpreter to do their job, and it can also be a chance for the interpreter to offload some of their feelings before they return to the outside world. This story, by an interpreter, illustrates what can happen when that opportunity is not provided.

\section{Case example}

'Thank you. The session went well. Do I have to sign your form?'. Once the form was signed, the CBT therapist shut the door. I stood there; the only sound the tap tap of a keyboard somewhere along the 
corridor. I turned to leave. I felt very strange, as if walking in another life. Something in that session had touched a raw nerve. I'd felt it, but in the sequence of interpreting I had not given it much thought. I could now feel the wave of emotions bubbling up inside me. I had to get out quickly before that feeling took over.

Often something within interpreting sessions leaves unresolved emotions in the interpreter. Spending a few minutes allowing the interpreter and the therapist to restabilise after the impact of the session should be part of the overall work of the CBT therapist/interpreter team.

This section finishes with a compilation of interpreters' own words about the impact the work can have on them.

'You can get home and it (the interpreting assignment) can impact on the relationship you have with friends and family. Because if you don't offload here it's going to come out. And sometimes in the wrong situations. Most clinicians will offer some support at the end of the session. You can't always remember, you can't always think, because during the session you're there 100\% trying to be professional, you don't let your emotions get in the way, you keep them buckled down. We are not machines. We are not Google Translate.'

Without 5 to 10 minutes at the beginning and end of a session, interpreters can be left 'emotionally naked' to enter or leave a therapy session. It seems only fair to give interpreters information about the session if it is available, so that they can prepare themselves for a distressing situation. Even in very busy contexts, briefing and debriefing is highly recommended so that there is space to think and learn, and so that burn-out can be avoided. Where possible, supervision groups can also be set up for interpreters (Costa, 2017; Costa, 2020).

\section{Summary, guidelines and tips}

Finding a way to work collaboratively together in the service of patients is a priority for therapists and interpreters and ultimately a benefit for all. Brief training interventions and appropriate ongoing supervision can ensure that the required skills are embedded into practice. Interpreter-mediated therapy is conducted within a system. If CBT therapists can broaden their thinking beyond the dyadic relationship within a therapy room, they will be better prepared to consider the wider issues before they emerge. Such a wide focus might even result in the trial of an in-house interpreter scheme. Other issues may include procedures with interpreting agencies and the therapist's preparation, both before therapy even begins, and in preparation for it to start. CBT therapists will need to think about how a patient and an interpreter find their ways to and from the consulting room, and to think about how they treat an interpreter as a valued and respected professional, while holding the clinical authority at all times, and negotiating their own position on the active-passive continuum.

In the 'Further reading and resources' section, you will find a link to a comprehensive set of guidelines for working with interpreters produced by the British Psychological Society.

The following is a brief set of tips abridged from the Mothertongue/Pásalo Good Practice principles for therapists when working with interpreters:

\section{Issues to observe:}

- Allow time for a pre-meeting with the interpreter to establish ways of working together.

- In the pre-meeting explain your working methods and expected outcomes to the interpreter.

- Let the interpreter know if you will be using any specific terminology.

- Arrange seating so that everyone can see each other.

- Clarify that you, the clinician, have ultimate responsibility for the session. It is necessary that the interpreter feels able to trust you to hold that responsibility. 
- In the session, speak directly to the patient.

- Introduce yourself and the interpreter. Think how you will manage beginnings and endings of sessions - is it OK for the interpreter and patient to be left alone?

- Set the ground rules including confidentiality and the fact that everything spoken by everyone in the room will be translated.

- Be transparent in the way you work.

- Reassure the patient about how important hearing their message and their voice is and how you will do your best to listen very carefully to them.

- Explain that you will be summarising and checking your understanding with the patient regularly.

- Reassure the patient about interpreting accuracy/confidentiality.

- Speak in small meaningful chunks so that the interpreter can translate accurately.

- Be aware of potential political conflicts between patients and interpreters who are from war-torn countries.

- Be aware of cultural differences and check if and how your patient experiences those differences.

- If the patient can speak some English, discuss together, between the three of you, how the interpreter can be most useful in the session (Talk about the Talking).

- Thank anyone from the family who wants to interpret so that they feel validated but explain that you are required to have a professional interpreter for your work. You may want to suggest that you might appreciate their support with other aspects of care if they are willing. It is important that the family member does not feel rejected or humiliated, for the wellbeing of everyone involved (Hadziabdic et al., 2014).

- Allow enough time for de-briefing at the end.

- Prepare in advance so that you allow enough time for the whole session.

- Work collaboratively together with the interpreter.

\section{Issues to avoid:}

- Use of jargon.

- Referring to the patient in the third person.

- Giving responsibility for the session to the interpreter.

- Speaking in unmanageable chunks.

- Leaving the interpreter and the patient alone together.

- Having a private conversation with the interpreter in the patient's presence.

- Expecting the interpreter to be a general assistant or to look after the patient.

\section{Key practice points}

(1) A more active facilitation stance is needed when working with an interpreter in order to manage the anxieties of all three participants in the triadic therapeutic encounter.

(2) A whole-system approach to working with an interpreter is useful, starting with familiarising yourself with agencies used and booking procedures, through to thinking about the type of support available for interpreters.

(3) A collaborative team approach to working with an interpreter enhances the effectiveness of interpreter-mediated CBT therapy.

Acknowledgements. I would like to thank the reviewers for their helpful suggestions. I would also like to thank Kamaljit Dosanjh, Joanna Mungai and Guida Shields, the interpreters who contributed to the paper with their helpful insights and examples. 
Author contributions. Beverley Costa: Conceptualization (lead), Investigation (lead), Methodology (lead), Project administration (lead), Writing - original draft (lead), Writing - review \& editing (lead).

Financial support. No financial support for this paper has been received.

Conflicts of interest. There are no conflicts of interest.

Ethical statement. No ethical approval was needed. The author has abided by the Ethical Principles of Psychologists and Code of Conduct as set out by the BABCP and BPS.

Data availability statement. Data availability is not applicable to this article as no new data were created or analysed in this study.

\section{Further reading and resources}

British Psychological Society Guidance - Working with interpreters online or via the telephone. https://www.bps.org.uk/sites/ www.bps.org.uk/files/Policy/Policy\%20-\%20Files/Working\%20with\%20interpreters\%20online\%20or\%20via\%20the\% 20telephone.pdf

Experiential, practical training courses for working effectively with spoken languages interpreters. https://www.pasaloproject. org/trainingconsultancy.html

NICE (2011). (Update of) Crossing the language barrier with a dedicated Mental Health Interpreting Service. https://www. nice.org.uk/sharedlearning/update-of-crossing-the-language-barrier-with-a-dedicated-mental-health-interpreting-service

The Royal College of Speech and Language Therapists guidelines for working with interpreters. https://3959e25e-b3e4-4cf092ed-b4c50fc1442d.filesusr.com/ugd/7f9695_e2618d3af15c43d5ab5057ad54e5cd97.pdf

Training films for therapists working with interpreters: https://www.pasaloproject.org/resources.html\#TIWT and https:// www.gla.ac.uk/research/az/gramnet/research/trainingmodel/

Multilingualism and mental health training resource. https://www.pasaloproject.org/multilingualism-mental-health-andpsychological-therapy-course-content.html

UNHCR Handbook for interpreters in asylum procedures. https://www.unhcr.org/dach/wp-content/uploads/sites/27/2017/ 09/AUT_Handbook-Asylum-Interpreting_en.pdf

\section{References}

Alexander, C., Edwards, R., \& Temple, B., (2004). Access to Services with Interpreters: User Views, York: Joseph Rowntree Foundation. https://www.jrf.org.uk/report/using-interpreters-access-services-user-views (accessed 7 August 2021).

Association of Sign Language Interpreters (2020). https://asli.org.uk/ (accessed 28 July 2021).

BABCP (2019). Black, Asian and Minority Ethnic Service User Positive Practice Guide. https://babcp.com/Portals/0/Files/ About/BAME/IAPT-BAME-PPG-2019.pdf?ver=2020-06-16-004459-320

BABCP (2021). Minimum Training Standards, https://babcp.com/Accreditation/Provisional-Accreditation/MinimumTraining-Standards

Bailey, C., McIntyre, E., Arreola, A., \& Venta, A. (2019). What are we missing? How language impacts trauma narratives. Journal of Child \& Adolescent Trauma, 13, 153-161. https://doi.org/10.1007/s40653-019-00263-3

Bernardes, D., Wright, J., Edwards, C., Tomkins, H., Dlfoz, D. \& Livingstone, A. G. (2010). Asylum seekers' perspectives on their mental health and views on health and social services: contributions for service provision using a mixed-methods approach. International Journal of Migration, Health and Social Care, 6, 3-19. https://doi.org/10.5042/ijmhsc.2011.0150

Bontempo, K., \& Malcolm, K. (2012). An ounce of prevention is worth a pound of cure: educating interpreters about the risk of vicarious trauma in healthcare settings. In Malcolm, K., \& Swabey, L. (eds), In Our Hands: Educating Healthcare Interpreters, pp. 105-130. Washington DC, USA: Gallaudet University Press.

Boyles, J., \& Talbot, N. (2017). Working with Interpreters in Psychological Therapy. London, UK: Routledge.

British Psychological Society (2017). Working with Interpreters: Guidelines for Psychologists, ed. Tribe, R. \& Thompson, K. doi: 10.13140/RG.2.2.24082.56009 BPS Report number: INF288/11.17 https:/www.bps.org.uk/sites/www.bps.org.uk/files/ Policy/Policy\%20-\%20Files/Working\%20with\%20interpreters\%20-\%20guidelines\%20for\%20psychologists.pdf

Costa, B. (2011). When Three is Not a Crowd: Professional Preparation for Interpreters Working with Therapists. ITI Bulletin January-February: 20-21.

Costa, B. (2017). Team effort - training therapists to work with interpreters as a collaborative team. International Journal for the Advancement of Counselling, 39, 56-69. https://doi.org/10.1007/s10447-016-9282-7

Costa, B. (2020). Other Tongues: Psychological Therapies in a Multilingual World. Monmouth: PCCS Books.

Costa, B., \& Briggs, S. (2014). Service-users' experiences of interpreters in psychological therapy: a pilot study. International Journal of Migration, Health and Social Care, 10, 231-44. doi: 10.1108/IJMHSC -12-2013-0044. 
Crezee, I., Jülich, S., \& Hayward, M. (2011). Issues for interpreters and professionals working in refugee settings. Journal of Applied Linguistics and Professional Practice, 8, 253-273.

Dallos, R., \& Vetere, A. (2012). Systems theory, family attachments and processes of triangulation: does the concept of triangulation offer a useful bridge? Journal of Family Therapy, 34, 117-137. https://doi.org/10.1111/j.1467-6427.2011. 00554.x

Doherty, S. M., MacIntyre, A. M., \& Wyne, T. (2010). How does it feel for you? The emotional impact and specific challenges of mental health interpreting. Mental Health Review Journal, 15, 31-44. https://doi.org/10.5042/mhrj.2010.0657

Hadziabdic, E., Albin, B., Heikkilä, K., \& Hjelm, K. (2014). Family members' experiences of the use of interpreters in healthcare. Primary Health Care Research \& Development, 15, 156-169. https://doi.org/10.1017/S1463423612000680

Karpman, S. (1968). Fairy tales and script drama analysis. Transactional Analysis Bulletin, 26, 39-43.

Lobban, F., \& Barrowclough, C. (2016). An interpersonal CBT framework for involving relatives in interventions for psychosis: evidence base and clinical implications. Cognitive Therapy and Research, 40, 198-215. https://doi.org/10. 1007/s10608-015-9731-3

Messent, P. (2003). From postmen to makers of meaning - a model for collaborative work between clinicians and interpreters. In Tribe, R. \& Raval, H. (eds.), Undertaking Mental Health Work Using Interpreters, pp.135-150. London, UK: Routledge.

Miller, K. E., Martell, Z. L., Pazdirek, L., Caruth, M., \& Lopez, D. (2005). The role of interpreters in psychotherapy with refugees: an exploratory study. American Journal of Orthopsychiatry, 75, 27-39. https://doi.org/10.1037/0002-9432.75.1.27

Renshaw, K. D., Steketee, G., \& Chambless, D. L. (2005). Involving family members in the treatment of OCD. Cognitive Behaviour Therapy, 34, 164-175. https://doi.org/10.1080/16506070510043732

Safran, J. D., \& Segal, Z. V. (1990). Interpersonal Process in Cognitive Therapy. Jason Aronson.

Salaets, H., \& Balogh, K. (2015). Co-Minor-IN/QUEST Research Findings. In K. Balogh, K., \& Salaets, H. (eds), Children and Justice: Overcoming Language Barriers. Cooperation in Interpreter-Mediated Questioning of Minors (pp. 175-326). Cambridge-Antwerp-Portland: Intersentia.

Thirlwall, K., Cooper, P., \& Creswell, C. (2017). Guided parent-delivered cognitive behavioral therapy for childhood anxiety: predictors of treatment response. Journal of Anxiety Disorders, 45, 43-48. https://doi.org/10.1016/j.janxdis.2016.11.003

Tribe, R., \& Lane, P. (2009). Working with interpreters across language and culture in mental health. Journal of Mental Health, 18, 233-241.

Tribe R., \& Thompson, K. (2009). Exploring the three-way relationship in therapeutic work with interpreters. International Journal of Migration, Health and Social Care, 5, 13-22. doi: 10.1108/17479894200900009

Tutani, L., Eldred, C., \& Sykes, C. (2018). Practitioners' experiences of working collaboratively with interpreters to provide CBT and guided self-help (GSH) in IAPT; a thematic analysis. The Cognitive Behaviour Therapist, 11, E3. doi: 10.1017/ S1754470X17000204

Cite this article: Costa B. Interpreter-mediated CBT - a practical implementation guide for working with spoken language interpreters. The Cognitive Behaviour Therapist. https://doi.org/10.1017/S1754470X2200006X 